\title{
Eggshell structure in Apteryx: Form, Function, and Adaptation
}

\author{
David Vieco-Galvez ${ }^{1}$, Isabel Castro ${ }^{1}$, Patrick Morel $^{1}$, Wei Chua ${ }^{1}$, and Michael Loh ${ }^{2}$ \\ ${ }^{1}$ Massey University College of Sciences \\ ${ }^{2}$ Fonterra Research and Development Centre
}

September 16, 2020

\begin{abstract}
The structure of Apteryx's eggshell has generated much debate over the decades because it does not fit well with most allometric predictions. Apteryx eggshells are unusually thin and have been reported to be $60 \%$ less porous than expected. It has been suggested that these adaptations are compensations for a very long incubation period. Most studies so far have been carried out in what has been reported as Apteryx australis, and using infertile eggs or eggs laid in captivity. However, A. australis once comprised all kiwi with brown plumage, now separated into three distinct species: Brown Kiwi (A.mantelli), Rowi (A.rowi), and Tokoeka (A.australis). These three species use different habitats and live at different latitudes and altitudes. In addition, captive eggs are much smaller than wild laid eggs. These confounding factors make necessary to revise the assumptions made for Apteryx in the past. In this study, we analysed the physical characteristics of the Apteryx eggshells making a comparison between the three species of brown coloured kiwi and for some of the analysis we included some specimens of Roroa (A. haastii, Great Spotted Kiwi). We found that shell characteristics are different between the different species studied. The pore area of Apteryx eggshells was higher than previously suggested, and the water vapour conductance was much closer to what is expected for an egg that size. We found several new features such as triangular mineral particles composing the cuticle, only reported for a cretaceous Theropod, and the presence of plugs and caps on the eggshell pores. We suggest that the characteristics of the eggshells of the different species relate to the mating system of each species in addition to environmental variables, particularly pluviosity. We also suggest that the erosion of the cuticle during incubation is an adaptation to a long incubation period in a burrow.
\end{abstract}

\section{Introduction}

Birds reproduce successfully in a wide range of ecosystems, including some of the most inhospitable ones. This is possible because birds present delicately balanced strategies to ensure the survival of their eggs (Carey 1980). These strategies imply the adaptative fine tuning of physiology, anatomy, and behaviour to respond to climatic regimes, predation, parasitism, and intraspecific competition. This is why such variety exists in the physical characteristics of eggs and eggshells, (Mikhailov, Bray, \& Hirsch, 1996, Portugal et al., 2014), nest architecture (Warning and Benedict 2015) and incubation behaviours (Deeming 2002) of birds. The relationships that exists between these adaptations means that using the characteristics of eggs, the nesting ecology of species could be better understood and vice versa (Tanaka et al. 2015). For example, several studies have hypothesised the nesting ecology of extinct species based on the physical characteristics of their fossilized eggshells (Deeming 2006, Grellet-Tinner et al. 2006, Varricchio et al. 2013). However, studying the physical characteristics of eggs and eggshells of extant species has the advantage that the nesting ecology does not need to be hypothesised but can be directly observed; and the relationship between the different adaptations to successful breeding in context, better understood.

The avian eggshell is a bioceramic composed of four mineral layers and two inner proteinaceous membranes (Romanoff and Romanoff 1949). The cuticle, the usually pigmented, outermost layer, has been proposed to have antimicrobial properties (Board and Fuller 1974), UV wavelength modulation properties, (Cooper 
et al. 2011), and water repellence, the latter being strongly associated with prevention against waterborne bacterial penetration (Sparks and Board 1984). These characteristics suggest that the cuticle responds to environmental conditions such as solar radiation and pluviosity, but also to the nest environment, mainly the probability of flooding and the potential for bacterial contamination (D'Alba et al. 2014, 2017).

The thickness of the eggshell is a functional character associated with structural support for the egg, reduction of bacterial infection as a solid barrier (Board and Fuller 1974) and more importantly, gas exchange, as the eggshell is a porous material (Rahn et al. 1974). The number and shape of pores are related to the incubation period (Zimmermann et al. 2007), altitude where the birds live (Rahn et al. 1977), and the nest microclimate (Birchard and Kilgore 1980). An additional contributor to eggshell thickness is the bioavailability of calcium and the mechanisms different species use to obtain calcium around the breeding season (Wilkin et al. 2009).

Eggshell porosity is a function of the pore functional area (mean area of individual pores multiplied by the total number of pores in an eggshell) and the thickness of the eggshell (Board and Scott 1980). These two characteristics of the eggshell define the gas conductance of the eggshell. Gas conductance is a measurement of the gas transfer through a medium (Rahn et al. 1974, Paganelli 1980, Rahn and Paganelli 1990). Gas exchange provides the embryo with the necessary oxygen for its development and allows carbon dioxide and water to leave the egg (Mueller et al. 2014, Maina 2017). This poses a series of constraints for different species incubating in different environmental conditions (Carey 1980). Birds in hot environments need to retain more water to avoid desiccation (Grant 1982) while species in cold or wet environments need to increase the water vapour conductance to lose enough water for the embryo to develop (Deeming 2011, Maina 2017). Further, some authors suggest that altitude is an important factor in regulating water vapour conductance due to the differences in barometric pressure that affect the rate of gas diffusion (Rahn et al. 1977, 1982). Therefore, it is expected that different species will present particular adaptations to regulate the water loss in different habitats and using different incubation techniques and nesting behaviours (Birchard and Kilgore 1980, Whittow et al. 1987, Portugal et al. 2010).

Water vapour conductance is particularly important for burrowing species, as these species' eggs are exposed to environments with high humidity, low concentrations of $\mathrm{O}_{2}$, and high concentrations of $\mathrm{CO}_{2}($ Boccs et al. 1984, Collias 1986). Therefore, it is expected that these species have adaptations in pore size and eggshell thickness to deal with these environments. In turn, burrow nesting may improve egg survivorship by providing better protection from predators and/or a more insulated environment for embryo development (Boggs and Kilgore 1983, Boccs et al. 1984, Whittow et al. 1987).

The Apterygidae family is endemic to New Zealand and it is characterised by a series of unique traits that are rare or not present in any other clade of birds, especially not found in other ratites (Ramstad and Dunning 2020). Among these traits are the egg's size, which is large in relation to bird size (Calder 1979, Taborsky and Taborsky 1999), comprising between 14-23\% of the female's body weight (Dyke and Kaiser 2010); the very thin eggshell compared to the size of the egg, which is $60 \%$ thinner than allometrically expected (Calder 1979), and the use of a burrow nest (Jolly 1989, Colbourne 2002, Vieco 2019).

Apteryx nests in globular cavities dug in the ground or existing cavities in dead trees or tree roots (Ziesemann et al. 2011) lined with nesting materials (Vieco 2019). And in Brown Kiwi the eggs are partially buried in the nest lining (Colbourne 2002). Apteryx is an unusual ratite as it has evolved to be mostly entirely nocturnal and primarily insectivorous (Cunningham and Castro 2011, Le Duc et al. 2015).

The genus Apteryx contains five well defined species distributed in the three main Islands of New Zealand and some offshore islands (Burbidge et al. 2003, Weir et al. 2016). Apteryx species present a very localized distribution due to the decline of their natural populations as a result of predation by introduced mammals and loss and fragmentation of habitat by deforestation (Germano et al. 2018). The climate encountered by Apteryx species varies from mild temperatures in the north of New Zealand to below zero temperatures and snow in the south (www.worldweatheronline.com). Therefore, adaptive variation in nesting behaviour between the differentApteryx species is expected as a response to each climatic regime.

Finally, Apteryx eggs are incubated for approximately 74 days in a humid, organic matter rich environment 
that is warmed periodically, which makes it ideal for the growth of micro-organisms (Hiscox 2014). Therefore, adaptive variation is expected between the different species in terms of the eggshell physical structure to respond to each climatic regime and the risk of microbial penetration.

A reduced porosity and water vapour conductance could be beneficial for a species with a long incubation period as it reduces the risk of desiccation and it is what has been estimated for Apteryx in the past (Calder 1979, Silyn-Roberts 1983). However, in most burrowing birds, a higher porosity and conductance has been observed because the humidity in a burrow can be closer to $100 \%$, thus reducing the rate of water diffusion from the egg. Differences in water vapour conductance can be achieved by means of increasing pore area or number, or by decreasing eggshell thickness (Ar and Rahn 1985). There are other adaptations that could compensate for the need of increased gas exchange concurrently with a need to prevent microbial contamination. For example, a reduction in pore size through mechanical means such as cuticular particles or opercula partially or fully plugging the pores (Board and Perrott 1979).

Some hypotheses about the function of the characteristics of the Apterygian egg and the eggshell to respond to certain ecological demands have been proposed. Reid (1971) proposed that the large Apteryxegg is a response to low temperatures during incubation that would select for an egg with higher volume-area ratio. Calder (1979) suggested that the increased amount of ovoinhibitors and lysozymes in the albumen of Apteryx eggs were selected to reduce the risk of microbial infection during the very long incubation period. Prinzinger and Dietz (2002) and Maloney (2008) suggested that the slow metabolic and developmental rate allows the egg to withstand long periods of abandonment. However, characteristics of the eggshell such as interspecific variation in eggshell thickness and water vapour conductance, that could help answer these questions are still not fully understood in Apteryx. Apteryx has been included in some studies on water vapour conductance variability in different species as an example of extreme adaptations (Calder 1979, Tullett 1984). However, this data has mostly been based on morphometric equations rather than direct measurements or using very few eggs from what was consideredApteryx australis, a species now known to comprise three species and further subdivided into nine (or more) different taxa (Weir et al. 2016). Especially outside New Zealand, samples are usually obtained from birds bred in captivity, which are known to produce eggs much smaller than those laid in the wild (Jensen and Durrant 2006). Some authors have tried to address these questions but unfortunately with very few eggs and eggshells (Silyn-Roberts 1983a), leaving this matter open to be researched in more depth.

In this study, we examined the eggshell structure of four species of Apteryx and contrast the findings with previous hypotheses regarding the expected structure based on environmental conditions where each species lives and their nesting environment. In summary, based on each species distribution it is expected that there will be differences in the water vapour conductance between the species. This should be observable as differences in pore density and pore area, or/and eggshell thickness. These traits are expected to vary according to climate, especially with pluviosity, temperature, and barometric pressure. It would also be expected that thickness scales with body mass (Birchard and Deeming 2009). We also expect to find eggshell adaptations to burrow nesting that are comparable to those of other burrow nesting birds, such as modified pores and modified cuticle or accessory layer.

\section{Materials and methods}

\section{Eggs}

Eggshell measurements were made on samples obtained from Operation Nest Egg (ONE), a program for the captive rearing of wild Apteryx eggs developed in 1994. Its purpose is to assist increasing wild population numbers by hatching wild-laid eggs in captivity and rearing the chicks until they gain enough weight to survive predation by introduced mammal species before release back into the wild (Colbourne et al. 2005). The eggs in this programme are generally collected after day 20 of incubation to increase the hatching success through artificial incubation. The eggs used in this study were retrieved after day 35 (range 35 to 60 ). After captive hatching eggshells were collected by staff members at Rainbow Springs, West Coast Wildlife Centre and Paparoa National Park and stored in sealable plastic bags with an identification code (collection locality 
and incubating male ID) and kept at room temperature until used in this study. The eggs are thoroughly cleaned upon arrival to the artificial incubation facilities.

Eggshells from 30 Brown Kiwi (A. mantelli), four Roroa (A. haastii ), 25 Rowi (A. rowi), and 20 Haast Tokoeka (A. australis australis ) from the 2013-2017 breeding seasons were used $(\mathrm{n}=79)$ (Table 1$)$. The eggshells originated from seven different locations in the two islands of New Zealand (Co-ordinates in Table 1, Figure 1A). All of the eggshells used for thickness came from hatched eggs to ensure that the ratio of calcium intake from the mammillae during ontogenesis (Deeming 2002) was approximately the same between all the samples and did not interfere with thickness measurements; also, to ensure the climatic comparisons were accurate the eggshells used for this observation came from eggs that hatched during a single breeding season, 2015-2016, since these comprised the majority of the samples. The eggshells were relatively intact except for the section broken by the chick during hatching. Different comparisons (statistical tests) used different number of eggshells depending on the initial state of the eggshells and the purpose of the comparison. Rahn and $\operatorname{Ar}(1980)$ suggested that pore distribution varies according to the latitude of the egg; therefore, for the water vapour conductance comparisons of the three brown Apteryx species samples were taken manually from the equatorial region of each eggshell (Figure 1B) to ensure accurate comparisons. This area of the egg was chosen for two reasons; because of hatching, the blunt end of most egg samples was destroyed, this being the usual exit point for the chick. In addition, for some of the samples the eggshells were somewhat crushed, and the equatorial region was the only identifiable part of the eggshell. However, some of the eggs were intact enough to identify different eggshell regions, these eggshells were used for the repeated measures analysis were the water vapour conductance of the different species and eggshells regions were compared.

We begin by making a description of the different species eggshells using a variety of optical techniques.

\section{Imaging techniques}

To determine the variation in porosity and thickness between species and the thickness of each structural layer, we used eggshell fragments from the equatorial region of eggs from each species. The fragments were manually broken and thoroughly washed in deionized water and allowed to air dry. The eggshells were relatively clean as they are cleaned thoroughly during artificial incubation.

\section{Micro-computed x-ray tomography (MicroCT)}

MicroCT (Zeiss) was used to determine the radii of pores and their geometry. Nine eggshell fragments (from the four species of Apteryx ) were used. The fragments were manually broken into three smaller fragments each, and a full scan of each fragment was used to observe the pore geometry. Images were obtained at $45 \mathrm{Kj}$, $133 \mu \mathrm{A}, 6 \mathrm{~W}$; a source distance of $20 \mathrm{~mm}$, detector distance at $8 \mathrm{~mm}$, pixel size of $1.9266 \mu \mathrm{m}$, objective magnification 10X, exposure time 11 seconds, and 1,000 projection images through 180@ of rotation. The images were analysed using Xradia mxct software. Images from the cuticle of all individuals were taken to see its physical features.

The pores of each fragment were counted, and their individual radii measured at three points along the pore, near the external opening, mid-way and close to the mammillary layer, these measurements were averaged to produce a mean pore radius.

\section{Scanning electron microscopy (SEM)}

\section{Eggshell Thickness}

SEM (FEI Quanta 200 ESEM, Eindhoven, Netherlands) was used to observe the thickness of the eggshell, the thickness of each constituent layer and external features. The samples were rinsed with reverse osmosis water to further remove any particles and allowed to air dry; samples were then mounted on aluminium stubs and gold spluttered with approximately $100 \mathrm{~nm}$ of gold in a vacuum (Baltec SCD 050 sputter coater). The images were taken by the Manawatu Microscopy and Imaging Centre (MMIC), using an accelerating voltage of $20 \mathrm{kV}$ and a spot size of 3 to 4 . For this technique, eggshells of 23 Brown Kiwi, 4 Roroa, 21 Rowi and 16 Haast Tokoeka were used. 
Images of the cuticle were resolved at $20 \mu \mathrm{m}$ resolution, cross sectional images and internal side images were produced at $300 \mu \mathrm{m}$. The measurements were analysed using ImageJ free software (Rueden et al. 2017).

\section{Pore radii}

The average pore radius was measured using SEM images of the external layer. Only images that showed opened pores in which the diameter could be measured were used $(\mathrm{N}=87)$, these images belonged to 28 individual eggs, and we used ImageJ to take three measurements of diameter per pore. These measurements were subsequently divided by two to estimate the radius and the radii were averaged per individual pore. A species average was used for further calculations and individual averages were used to compare with microCT radius measurements. However, no statistical model was used due to the small sample size per species used in the microCT.

\section{Dissecting microscope}

The pore density of the three species eggshells was observed under a dissecting microscope (Olympus SZX12). Three eggshell fragments from the equatorial region of Brown Kiwi (13), Rowi (12), and Haast Tokoeka (10) were washed in an ultrasonic bath filled with deionized water to remove the plugs from the pores, let air dry and stained with an alcohol-based solution of Malachite green (1\%). The eggshells were placed on paper towels and two drops of the dye were applied to the inner eggshell surface. The eggshells were let to set to allow the dye to penetrate the pores without staining the cuticle (Figure 2C).

The eggshells were observed under stereo microscope (Olympus SZX12) and photographed using an attached camera (Olympus S30) and then the pores were individually counted using ImageJ. The eggshells from the same individuals were later used in the Water Vapour Conductance experiments. This way the average pore density was estimated (pores $\left./ \mathrm{cm}^{2}\right)$.

\section{Water vapour conductance}

We used an alternative method for the estimation of the water vapour conductance by using the eggshells following the methodology reported by Portugal et al. (2010), instead of using a whole infertile egg (Ar and Rahn 1985). Fragments from the equator of the eggshell $(\mathrm{N}=62)$ from the three species were glued (inside down) onto a PCR tube (SSI, $0.5 \mathrm{ml}$, Cat. No. 1110-02) filled with $200 \mu \mathrm{L}$ of distilled water. The tubes were placed in PCR trays for easy handling and the trays placed in a desiccator containing $550 \mathrm{~g}$ of colour-indicating silica gel and the desiccator in a controlled temperature room at $25^{\circ} \mathrm{C}$. Water loss was measured every 24 hours for a period of three days by weighing the tubes. Eggshells from commercially produced chicken eggs where included in this experiment as control to determine if the values obtained in this experiment were congruent with those reported in the literature. Separately, fragments from different eggshell regions of eggs that were intact enough for each region to be recognised, were used in the same way. The fragments were taken from the blunt end (B), the acute end (A) and the equator (E) (Figure 1B). The purpose for this was to determine if there were differences between the different eggshell regions and according to species.

We determined the daily water loss $\left(M_{\mathrm{H}_{2} \mathrm{O}}\right)$ by weight loss and calculated the water vapor conductance as: $G_{\mathrm{H}_{2} \mathrm{O}}=M_{\mathrm{H}_{2} \mathrm{O}} / P_{\mathrm{H}_{2} \mathrm{O}} E q .1$

Where is the water vapor conductance, and is the pressure difference at standard conditions ( 1 atmosphere and $25^{\circ} \mathrm{C}$ ). The air cell pressure and nest environment pressure difference has been calculated for most avian species, including burrow nesters $\left(23.77 \mathrm{mg} \cdot \mathrm{d}^{-1} \cdot\right.$ torr $\left.^{-1}\right)$. Therefore, we used this value as the water pressure difference $\left(P_{\mathrm{H}_{2} \mathrm{O}}\right)$.

\section{Water vapour conductance of eggs during incubation}

ONE incubates eggs at a constant temperature of $35.5^{\circ} \mathrm{C}$ and maintains humidity constant at about $60 \%$. As part of their protocol eggs are weighted upon arrival and before hatching, to account for excessive water loss. Using this information, we calculated the water vapour conductance of the eggs under these circumstances, 
with the intention of obtaining a value of water vapour conductance of the whole egg in addition to the water vapour conductance of individual eggshell fragments. We used the relative humidity equation to correct for these conditions and calculated the partial pressure in the artificial incubator, thus calculating the pressure difference across the eggshells (considering that the pressure difference is 23.77 Torr in $0 \%$ humidity).

$p_{\mathrm{H}_{2} \mathrm{O}}=\frac{\mathrm{RH} * p^{*}{ }_{\mathrm{H}_{2} \mathrm{O}}}{100 \%}$

Eq. 2

Here, $p_{\mathrm{H}_{2} \mathrm{O}}$ is the partial pressure of water vapour in the incubator, $\mathrm{RH}$ is the relative humidity (60\%), and is the total pressure of water vapour at $35.5^{\circ} \mathrm{C}$. Once the water vapour conductance was calculated for these conditions, the water loss was calculated for the standard conditions $\left(25^{\circ} \mathrm{C}\right.$ and $0 \%$ humidity) using the formula developed by Ar et al., (1974):

$\dot{M}_{\mathrm{H}_{2} \mathrm{O}}=c * D_{\mathrm{H}_{2} \mathrm{O}} * \frac{\mathrm{Ap}}{L} * P_{\mathrm{H}_{2} \mathrm{O}}$

Eq. 3

Where is the daily water loss, $C$ is a conversion constant $\left(155.52^{*} 107 / \mathrm{R}^{*} \mathrm{~T}\right.$, where $\mathrm{R}$ is the ideal gas constant:6.24*104cm $3^{*}$ Torr $/ \mathrm{mol}^{* \circ} \mathrm{K}$, and $\mathrm{T}$ is absolute temperature in ${ }^{\circ} \mathrm{K}$ ), is the diffusion coefficient of water in air at a given temperature (in $\left.{ }^{\circ} \mathrm{C}\right), \mathrm{Ap} / \mathrm{L}$ is porosity, and the difference in pressure across the eggshell. From this using equation 3.5 water vapour conductance of whole eggs at 25 and $0 \%$ humidity was calculated and compared with the results reported by Calder (1978) and Silyn-Roberts (1983) for Brown Kiwi, and with the values reported by Ar et al. (1974) for other avian species.

The water vapour conductance was calculated by using the daily water loss calculated from equation (3) in equation (1). Finally, to compare our results with allometric predictions we calculated the water vapour conductance for those eggs based on Ar et al. (1974):

$G_{H_{2} \mathrm{O}}=0.432 * W^{0.780} E q .4$

Where $\mathrm{W}$ is the fresh weight of the egg, in this case we used the arrival weight of the eggs since there was no way to know the fresh egg weight. In this measurement only Brown Kiwi eggs were used as were the only ones that were weighed before hatching so the water loss could be determined.

\section{Statistical analysis}

A discriminant analysis was used to determine the degree of association of each eggshell sample with the donor species to determine the degree of differentiation between the four species of Apteryx. This was done to determine if the eggshells of Brown kiwi, Rowi, Roroa, and Haast Tokoeka were different and could be associated with environmental variables. For this, we used weather information from the area the egg was collected; the average monthly temperature, pluviosity, and barometric pressure from April 2015 to February 2016 was obtained from worldweatheronline.com. A spearman rank correlation was performed for eggshell thickness, pore density, and pore radius with each of the mentioned climatic variables.

A one-way ANOVA was performed using the samples from Brown kiwi, Rowi and Haast Tokoeka to determine if there was a significant difference in terms of eggshell thickness and cuticular thickness; Roroa was not included in this or any further analysis, as the sample size of eggs was too small.

An ANOVA was used to test if there were differences in water vapour conductance between the species and a nested linear model was used to test the different eggshell regions. In this case the fragments (E, A and B) were nested within species. All the ANOVA's performed in this study were followed by a Tukey post hoc test to assert which species differ from each other. A repeated measures ANOVA was used to determine the difference in water vapour conductance of three different regions of the eggshell of Brown kiwi, Rowi and Haast Tokoeka, and to determine the extent of the interaction of the species and the region of the eggshell.

A paired T-test was performed to compare the water vapour conductance of whole Brown Kiwi eggs being incubated by ONE and the water vapour conductance calculated from Eq. 6. using the mass of the egg. All 
the statistical analysis in this study were made using MiniTab 18 Statistical Software.

\section{Results}

\section{The different layers of the Apteryx eggshell}

Apteryx eggshells showed a clear demarcation between the four constituent layers (Figure 3). With exception of the mammillary layer (ANOVA, $\mathrm{F}=1.85, \mathrm{p}=0.150 ; \mathrm{n}=59$ ), the constituent layers of the eggshell showed variation between species. The proportion of cuticle from the total eggshell thickness (ANOVA, $\mathrm{F}=8.85$, $\mathrm{p}<0.001 ; \mathrm{n}=59)$ and the proportional thickness of the crystalline and palisade layers $(\mathrm{F}=6.76, \mathrm{p}=0.001$; $\mathrm{n}=59$ ) varied significantly between the four Apteryx species (Figure 3).

\section{Interspecific comparison}

\section{Discriminant analysis}

Using simultaneously the thickness of the eggshell, the mammillary density and area, and the thickness of the different constituent layers it was possible to associate a particular eggshell to its right species in $78 \%$ of the cases (Brown Kiwi $=76.5 \%$, Roroa $=75 \%$, Rowi $=78.9 \%$, Tokoeka $=80 \%$ ).

\section{The cuticle (or external layer)}

All Apteryx species presented thin cuticles with a wax-like appearance, which in contrast to the smooth sponge like texture of the crystalline layer made it easy to identify (Figure 2A). Seen from outside the cuticle was smooth and unpigmented, pores seemed to radiate from underneath the cuticle (Figure 2B).

The cuticle thickness decreased significantly with latitude, being thicker in Brown Kiwi and thinnest in Rowi and Tokoeka; the significance was due to differences between Brown Kiwi and Rowi (Table 3). Under the micro CT scan, the crystalline structure of the cuticle became apparent, and it was possible to discern the individual crystals that formed it (Figure 4).

\section{The Pores}

Some pores were hard to identify in the external images of the eggshells because a "cap" made from the same mineral as the cuticle (Figure 5) covered them. Apteryx eggshells had cylindrical (or funnel shaped) pores that usually crossed the thickness of the eggshell slightly on an angle. In each fragment, very few pores reached the cuticle surface of the eggshell, with most reaching only half or less of the total thickness of the eggshell and many smaller pores that barely went beyond the mammillary layer (occluded pores, Figure $5 \mathrm{~A})$.

The observations made using the micro CT were confirmed by Scanning Electron Microscopy images of the exterior of the eggshells, where in some cases caps were seen covering the pores and in others mineral occlusions were observable (Figure 6). These caps and occlusions were observed in all four species and in all individuals.

Accordingly, fewer pores were visible at the cuticle side of the egg and many more from the inside. Since the CT is an X-ray technique, it is possible to see at different "depths" through the eggshell. When observed near the cuticle few pores were discernible but when looking at midway between the cuticle and the mammillae more pores become visible, confirming what was seen in the cross sections (Figure 6D, E).

\section{Pore radius and pore density}

Pore size measured as pore radius was different between the southern species and Brown Kiwi, the latter having smaller pores; pore density in contrast was higher in Brown Kiwi and lowest in Tokoeka. The measurements taken using MicroCT were in accordance with those obtained with SEM, except for Tokoeka. In Tokoeka the pores seemed to thin midway, having a larger outside opening and a broader base (Table 4).

\section{Eggshell thickness}


Eggshell thickness varied with species and seemed to follow a latitudinal pattern with thinner eggshells in the northernmost species and thicker eggshells in the southernmost species (Table 3); Roroa was not included in the ANOVA because of the small sample size, but the eggshell thickness is indicated in the table.

\section{Climatic variables}

All the climatic variables showed moderate to low correlations with eggshell physical parameters (Table 5). Pluviosity showed significant relationships with all the eggshell physical characteristics, while pore density was not correlated with temperature or barometric pressure. Thickness was moderately associated with pluviosity, temperature and barometric pressure, and all these associations were significant.

\section{Water vapour conductance}

The three species of Apteryx differed significantly in the water vapour conductance of their eggshells (Figure 7A), with Brown Kiwi having a significantly higher water vapour conductance when compared to Tokoeka $(\mathrm{F}=3.87, \mathrm{p}=0.001)$, and Rowi being significantly different to Tokoeka $(\mathrm{F}=2.06, \mathrm{p}=0.05)$. Rowi did not differ significantly from Brown Kiwi $(\mathrm{F}=1.91, \mathrm{p}=0.062)$; however, this comparison could be considered close to being significant. The different regions of the eggshell confirmed existing differences in water vapour conductance between species, however Rowi being the only one significantly different, marginally when compared to Brown Kiwi ( $\mathrm{T}=-2.11, p=0.05)$ and significantly when compared to Tokoeka $(\mathrm{T}=2.59, p$ $=0.02$ ), also only the blunt end was significantly different to the other two regions for the three species. There was no interaction between species and fragment (Table 6).

\section{Water vapour conductance of eggs during incubation}

The water vapour conductance of whole eggs was significantly different to that calculated from allometric equations using the egg's mass $(\mathrm{df}=19, \mathrm{~T}=3.86, \mathrm{p}=0.001)$ (Figure $7 \mathrm{~A})$.

We compared the water vapour conductance calculated in this study for whole incubated eggs with that reported in the literature (Table 7). Calder (1978a) used infertile eggs and the methodology employed by Rahn et al., (1974). Sylin-Roberts (1983) devised a method for calculating the pore number and pore area and calculated the water vapour conductance of the whole egg from three eggshell fragments. Both these studies were done on Apteryx australis eggs and eggshells, but at this time, Apteryx australis included A. mantelli, $A$. rowi, and A. australis .

We plotted the resulting water vapour conductance alongside the data published by Ar et al.,1974, where they demonstrated how the water vapour conductance is proportional to the 0.78 power of the eggs mass (Figure 8). Here we show how the water vapour conductance of Brown Kiwi fits perfectly with what is observed for other species.

\section{Discussion}

In this study, we found that the eggshells of four of the five species of Apteryx (Brown kiwi, Rowi, Roroa, and Haast tokoeka) were different enough to be assigned to their corresponding species using morphological characters. Whether these differences are due principally to phylogeny or ecology is debatable. Some of the species have suffered severe contraction to their ranges and all individuals left remain in a single population (i.e. Rowi and Roroa). Eggshells' characteristics within a species (i.e. chickens) are known to be affected by environmental conditions (Rahn et al. 1982), and other studies have shown that the characteristics we measured in this study are strongly affected by the environmental conditions that individual birds live in (Winkler and Sanchez-Villagra, 2006; D'Alba et al., 2017). Therefore, in the next paragraphs we will discuss the possible ecological conditions that could explain these characters.

\section{Cuticle and Eggshell}

We found that the Apterygian cuticle consisted of a very thin, waxy, water repellent mineral layer composed of triangular particles; that at times, formed aggregations that occluded eggshell pores. We also found that all the studied species of Apteryx presented plugged or capped pores. From our observations it seems possible 
that the cuticle of Apteryx erodes over time, from a more sealed egg when freshly laid to a more porous one, as the embryo develops and requires a greater gas exchange. We also found that many pores did not go all the way through the eggshell, a similar observation was mentioned by Silyn-Roberts (1983) nevertheless, the function of these types of pores is still not clear. Similar pores that do not transverse the eggshells have been observed in the eggs of Ostriches (Struthio camelus ), a relative of Apteryx (Willoughby et al., 2016; Maina, 2017).

The cuticle and eggshell mediate the interaction between the developing embryo and the environment. As such, they are the first barriers against pathogens and allow gas exchange and water vapour conductance (D'Alba et al. 2017). Features of the cuticle such as plugs, and caps have been associated with nesting in humid environments (D'Alba et al. 2016) as they block the pores. Board (1981) suggested that plugs could also serve as a physical barrier to defend the egg contents particularly against waterborne microbes. Apteryx species breed during the austral winter, which in New Zealand is characterised by frequent and heavy precipitation (Leathwick et al. 2002); they lay their eggs in burrows with a relatively humid environment and their incubation period is long. We found that pluviosity was significantly associated with eggshell thickness, pore density and pore radius.

A thicker eggshell means longer pores, reducing the number and area of the pores could be an adaptation to prevent water to penetrate the egg. This seems even more plausible considering that other adaptations, such as plugs, and caps seem to point in the same direction. Apteryxnests are frequently holes in the ground, this, with an incubating parent that could return to the nest with a wet plumage seems to indicate that the kiwi incubates in a very wet environment. Which in turn it would be expected to increase the humidity of the nest, making very necessary that future studies measure the humidity of nests in rainy areas such as Okarito or Haast, areas inhabited by Rowi and Tokoeka respectively, furthermore, Okarito experiences frequent snow (up to $1 \mathrm{~m}$ in the past 10 years); studying the nest architecture of Rowi and Tokoeka would clarify further the nature of the different characteristics present in the Apterygian eggshell.

Apteryx does not present the accessory layer described in Megapodidae, Phoenicopteridae, and Podicipedidae (Tullett et al. 1976, Board et al. 1984, D'Alba et al. 2017) and that has been associated with decreasing bacterial penetration in high humidity environments. It seems that Apteryx might achieve a more sealed egg with a water-repellent smooth cuticle that erodes as gas diffusion needs increase with the progression of embryo development.

Temperature and barometric pressure play a very important role in gas diffusion; higher temperatures and lower pressures allow the gases to diffuse at faster rates. Water vapour conductance and gas exchange can be modulated by variations in the number, length, shape, and diameter of pores and by obstructions in the pores. For example, water vapour conductance and gas exchange can be lowered by having less pores per area, longer pores, branched pores, and by increasing the number of caps and plugs or unperforated pores. Therefore, the number and shape of pores have been found to be related to incubation period (Zimmermann et al. 2007), altitude where the birds live (Rahn et al., 1977), and the nest microclimate (Birchard and Kilgore, 1980).

Eggshell thickness and pore radius showed a moderate to low negative correlation with barometric pressure. At lower barometric pressures water diffusivity increases therefore eggs are at higher risk of desiccation, hence a thicker eggshell and smaller pore would reduce the water vapour conductance accordingly. The opposite is true for higher barometric pressures; however, in this case the eggshell must also stand a greater overall pressure on its structure, therefore a thickened eggshell would be beneficial. In chickens, a move from an altitude of 3800 masl to 1200 masl resulted in an increased eggshell thickness with decreased pore radius to compensate for the increase in barometric pressure (Rahn et al. 1982). Similar correlations occurred between temperature and eggshell thickness and pore radius.

Eggshell thickness is known to be proportional to the body mass of the laying bird (Tullett 1978, Birchard and Deeming 2009). However,Apteryx species vary in their incubation behaviour. In Brown Kiwi the male is the sole incubator, while in Roroa and Rowi both male and female incubate and in Tokoeka, there are 
helpers at the nest, requiring further studies relating both the female and the male body sizes to the egg and the eggshell, it is worth to notice that the egg mass is very high in relation to body mass, being 23.6 and $14.6 \%$ for A.oweniiand A. australis (possibly A.mantelli) (Dyke and Kaiser 2010). Apteryx eggshells are allometrically thinner than expected and this is probably to reduce the weight the female must carry (Calder 1979) and to allow chicks to crack the shell when hatching, as Apteryx does not possess an egg tooth (Calder 1978). The trade-off is then that a thinner eggshell is more prone to mechanical damage and even hairline fractures have been known to impact embryo health and development (Sylin-Roberts 1980; Stadelman 1995). In our study, the lightest (on average) of the four species, the Rowi had a thicker eggshell than the heavier Brown Kiwi; also, the Roroa, the heaviest of Apteryx had a thinner eggshell than the lighter Haast Tokoeka.

We suggest that the different incubation strategy of each species could also influence the evolution of eggshell thickness. In Tokoeka both males and females incubate, females are larger than the males and this could have been a selective pressure for a thicker eggshell that evaded breakage. In contrast, in the lighter Brown Kiwi generally only the males incubate. Rowi, being the smallest of the three species, presents an eggshell thickness similar to that of Haast Tokoeka but in contrast to Brown Kiwi, both male and female have been observed incubating (Colbourne 2002).

\section{Pores, gas exchange and water vapor conductance}

Prior to this study the understanding was that the water vapour conductance of Apteryx was $65 \%$ lower than expected by allometric predictions because of low porosity in relation to egg mass, and as a compensation for a very long incubation period (Tullett 1984). The water vapour conductance we measured using shells was in accordance to that measured for ground burrowing species reported by (Portugal et al. 2014). The different eggshell regions showed different water vapour conductance indicating a difference either in thickness or pore density. In some eggs, it was possible to observe a cluster of pores concentrated in the most apical extreme of the blunt end; however since the eggshells used in the study came from hatched individuals in most cases this particular region had fractures and a neighbouring fragment was used, possible underestimating the actual number of pores of that region, nevertheless it has been noted that the air-cell of Apteryx is off centre (Rowe 1978). Significant differences were seen between the blunt end and the acute end for Brown Kiwi and Rowi in water vapour conductance, it is possible that this is also the case for Haast Tokoeka but because of the difficulty of sampling this was not observed. Differences in porosity in different eggshell regions have been reported for ducks and gulls (Portugal et al. 2010), but the purpose of this trait has not been discussed.

The water vapour conductance of the whole egg was almost twice as high than previously reported at 40.84 $\mathrm{mg} /$ day.torr compared to 26.00 and $23.71 \mathrm{mg}$ /day.torr reported by Calder (1978) and Silyn-Roberts (1983) respectively. Furthermore, when compared with the values reported by Ar et al.,1974 for a variety of avian species, Apteryx mantellifitted perfectly into the expected relationship between egg mas and water vapour conductance, meaning that the egg loses water in the same proportion as any other avian egg. However, these calculations were made towards the end of the incubating process as opposed to the previous studies which used freshly laid eggs.

Calder (1978) stated that Kiwi's eggshell porosity was $60 \%$ of the predicted value by Ar et al., (1974) equation. However, we found that pore density and pore radius were greater than previously measured, indicating that porosity should be higher, this in conjunction with plugged pores could explain what this was found in the past. In his study, Calder (1978) used eggshells from infertile eggs, where the cuticle would be intact and occlusions in place, this could explain why when the pores where counted, the porosity was under-estimated leading to exaggerated assumptions regarding the water vapour conductance of Apteryx. The eggshells we used belonged to successfully hatched eggs, meaning that if there was any abrasion or pore opening, pores would be more visible at this stage than in an infertile egg. This still needs to be tested by comparing the porosity of freshly laid eggs versus the porosity of successfully hatched eggs in the wild.

Our observations suggest that the cuticle becomes thinner through the incubation process. We suggest that this wearing results in more open pores with plugs, and occlusions disappearing and even some unperforated pores reaching the surface of the shell as the embryo develops allowing greater gas exchange and water 
vapour conductance. This would make sense for a species with a long incubation period in an underground nest, as capped pores could help reduce the risk of microbial contamination in early stages of development where oxygen is barely required. Prinzinger et al. (1995) reported that precocial embryos would drastically increase the oxygen consumption later in the incubation period, by this point Apteryx could have "polished" the eggshell allowing an increased gas exchange, by that time the defences remaining in the albumin would help protecting the embryo until hatching. The cuticle has been observed to help modulating to some extent the gas exchange in the domestic fowl (Peebles and Brake 1986); it would be then necessary to compare further incubated and unincubated Apteryx eggshells to determine if something similar occurs in these species.

A similar increase of water vapour conductance during incubation has been suggested for Adelie Penguins (Pygostelis adeliaei ) to cope with the extreme aridity of the Antarctic (Thompson and Goldie 1990); similarly, a reduction in pore thickness by mammillary and pore erosion has been suggested for the Mallee Fowl (Leipoa ocellata) as a mechanism to increase water vapour conductance during a long incubation period in a high humidity and low oxygen environment (Booth and Seymour 1987). These observations suggest that water vapour conductance does not remain constant throughout the entire incubation process. Furthermore, some of these adaptations could give an advantage to birds to adjust water loss according to immediate ecological demands.

The triangular particles in the cuticle of Apteryx have not been reported for any other bird, but similar ones were observed in the fossil eggshells of Trigonoolithus amoae a theropod from the lower cretaceous period found in La Cantalera, Spain (Moreno-Azanza 2013). Since it has been suggested that many dinosaurs might have buried their eggs (Tanaka et al. 2015), and there is evidence of a nesting theropod (Oviraptor philoceratos ) which might have similar nesting behaviours to modern ratites (Norell et al. 1994), it could be possible to suggest that these triangular particles play some role related to the nest environment.

The eggshell characteristics found in this study suggest that Apteryx species are adapted to the environmental conditions where the eggs are incubated, and possibly the breeding strategies. Each characteristic may be explained by more than one factor suggesting that it is the synergy between the factors that shaped the eggshells of the different species.

\section{Acknowledgements}

Thanks to the Operation Nest Egg projects that contributed samples to our study, Rainbow Springs Nature Park, Rotorua; West-Coast Wildlife Centre, Franz Joseph, and the rangers of Paparoa National Park. Especial thanks to Claire Travers for her constant support and input to the project. Thanks to Nikki Minards and the Manawatu Microscopy Centre for producing the scanning electron microscopy images. Especial thanks to Aryaman Parulkar and Lucas Mugnier who aided in the cutting, staining, and preparing of samples for various experiments and observations. Funding from Security for Iconic Species: Kiwi Rescue' MBIE Programme C09X1609 supported IC.

\section{Authors' Contribution}

DV and IC conceived the idea. All authors contributed critically to designing the methodology, DV collected and analysed the data with help from PM. All authors contributed critically to the writing of the manuscript and gave final approval for publication. ML collected micro CT scans and helped with their interpretation.

\section{Declarations}

Eggshells from hatched eggs were used as conservation policies of these endangered species are very strict and would not allow risking or ending the life of any bird, and we acted according to the permits obtained from the Department of Conservation of New Zealand (Authorisation number: 56537-DOA) .

\section{Data accessibility}

All authors have agreed to archive the morphological data in Dryad. 


\section{References}

Ar, A. and Rahn, H. 1985. Pores in avian eggshells: Gas conductance, gas exchange and embryonic growth rate. - Respir. Physiol. 61: 1-20.

Ar, A., Paganelli, C. V, Reeves, R. B., Greene, D. G. and Rahn, H. 1974. The avian egg: water vapor conductance, shell thickness, and functional pore area. - Condor 76: 153-158.

Birchard, G. F. and Kilgore, D. L. J. 1980. Conductance of Water Vapor in Eggs of Burrowing and Nonburrowing Birds: Implications for Embryonic Gas Exchange. - Physiol. Zool. 53: 284-292.

Birchard, G. F. and Deeming, D. C. 2009. Avian eggshell thickness: Scaling and maximum body mass in birds. - J. Zool. 279: 95-101.

Board, R. G. 1981. The microstructure of avian eggshells, adaptive significance and practical implications in aviculture. - Wildfowl 32: 132-136.

Board, R. G. and Fuller, R. 1974. Non-specific antimicrobial defences of the avian egg, embryo and neonate.

- Biol. Rev. Camb. Philos. Soc. 49: 15-49.

Board, R. G. and Perrott, H. R. 1979. The Plugged Pores of Tinamou (Tinamidae) and Jacana (Jacanidae) eggshells. - Ibis 121: 469-474.

Board, R. G. and Scott, V. D. 1980. Porosity of the avian eggshell. - Integr. Comp. Biol. 20: 339-349.

Board, R. G., Perrott, H. R., Love, G. and Scott, V. D. 1984. The phosphate-rich cover on the eggshells of grebes (Aves: Podicipitiformes). - J. Zool. 203: 329-343.

Boccs, F., Kilgore, D. L. and Birchard, G. F. 1984. Respiratory Physiology of Burrowing Mammals and Birds. - Comp. Biochem. Physiol. 77A: 1-7.

Boggs, D. F. and Kilgore, D. L. J. 1983. Ventilatory responses of the burrowing owl and bobwhite to hepercarbia and hypoxia. - J. Comp. Physiol. 149: 527-533.

Booth, D. and Seymour, R. S. 1987. Effect of eggshell thinning on water vapor conductance of malleefowl eggs. - Condor 89: 453-459.

Burbidge, M. L., Colbourne, R. M., Robertson, H. A. and Baker, A. J. 2003. Molecular and other biological evidence supports the recognition of at least three species of brown kiwi. - Conserv. Genet. 4: 167-177.

Calder, W. A. 1978. The Kiwi: A Case of Compensating Divergences From Allometric Predictions. - In: Respiratory function in Birs, Adult and Embryonic. pp. 239-242.Springer, Berlin, Hildelberg.

Calder, W. A. 1979. The kiwi and egg design: evolution as a package deal. - Bioscience 29: 461-467.

Carey, C. 1980. The Ecology of Avian Incubation. - Bioscience 30: 819-824.

Colbourne, R. 2002. Incubation behaviour and egg physiology of kiwi (Apteryx spp. ) in natural habitats. - N. Z. J. Ecol. 26: 129-138.

Colbourne, R., Bassett, S., Billing, T., McCormick, H., McLennan, J., Nelson, A. and Robertson, H. 2005. The development of Operation Nest Egg as a tool in the conservation management of kiwi. - Sci. Conserv.: $1-24$.

Collias, N. 1986. Engineering aspects of nest building by birds. - Endeavour 10: 9-16.

Cooper, C. B., Voss, M. A., Ardia, D. R., Austin, S. H. and Robinson, W. D. 2011. Light increases the rate of embryonic development: Implications for latitudinal trends in incubation period. - Funct. Ecol. 25: $769-776$.

Cunningham, S. J. and Castro, I. 2011. The secret life of wild brown kiwi: Studying behaviour of a cryptic species by direct observation. - N. Z. J. Ecol. 35: 209-219. 
D'Alba, L., Jones, D. N., Badawy, H. T., Eliason, C. M. and Shawkey, M. D. 2014. Antimicrobial properties of a nanostructured eggshell from a compost-nesting bird. - J. Exp. Biol. 217: 1116-1121.

D'Alba, L., Maia, R., Hauber, M. E. and Shawkey, M. D. 2016. The evolution of eggshell cuticle in relation to nesting ecology. - Proc. R. Soc. B Biol. Sci. 283: 20160687.

D'Alba, L., Torres, R., Waterhouse, G. I. N., Eliason, C., Hauber, M. E. and Shawkey, M. D. 2017. What Does the Eggshell Cuticle Do? A Functional Comparison of Avian Eggshell Cuticles. - Physiol. Biochem. Zool. 90: 588-599.

Deeming, D. C. 2002. Avian incubation : behaviour, environment and evolution. - Oxford : Oxford University Press, 2002.

Deeming, D. C. 2006. Ultrastructural and functional morphology of eggshells supports the idea that Dinosaur eggs were incubated buried in a substra. - Palaeontology 49: 171-185.

Deeming, D. C. 2011. Importance of nest type on the regulation of humidity in bird nests. - Avian Biol. Res. 4: 23-31.

Dyke, G. J. and Kaiser, G. W. 2010. Cracking a developmental constraint: egg size and bird evolution. Rec. Aust. Museum 62: 207-216.

Germano, J., Barlow, S., Castro, I., Colbourne, R., Cox, M., Gillies, C., Hackwell, K., Harawira, J., Impey, M., Reuben, A., Robertson, H., Scrimgeour, J., Sporle, W. and Yong, S. 2018. Kiwi Recovery Plan 2018-2028 / Mahere Whakaora Kiwi 2018-2028. Threatened Species Recovery Plan 64.: 60.

Grant, G. . 1982. Avian Incubation : Egg Temperature, Nest Humidity, and behavioral thermoregulation in a hot environment. - Am. Ornithol. Union: 1-75.

Grellet-Tinner, G., Chiappe, L., Norell, M. and Bottjer, D. 2006. Dinosaur eggs and nesting behaviors: A paleobiological investigation. - Palaeogeogr. Palaeoclimatol. Palaeoecol. 232: 294-321.

Hiscox, J. D. 2014. Can microbes be contributing to the decline of the North Island Brown Kiwi (Apteryx mantelli )? : [Masters thesis] Massey University, Palmerston North, New Zealand.

Jensen, T. and Durrant, B. 2006. Assessment of reproductive status and ovulation in female brown kiwi (Apteryx mantelli ) using fecal steroids and ovarian follicle size. - Zoo Biol. 25: 25-34.

Jolly, J. N. 1989. A field study of the breeding biology of the little spotted kiwi (Apteryx owenii ) with emphasis on the causes of nest failures. - J. R. Soc. New Zeal. 19: 433-448.

Le Duc, D., Renaud, G., Krishnan, A., Almen, M. S., Huynen, L., Prohaska, S. J., Ongyerth, M., Bitarello, B. D., Schioth, H. B., Hofreiter, M., Stadler, P. F., Prufer, K., Lambert, D., Kelso, J. and Schoneberg, T. 2015. Kiwi genome provides insights into evolution of a nocturnal lifestyle. - Genome Biol. 16: 147.

Leathwick, J. R., Wilson, G. and Stephens, R. T. T. 2002. Climate Surfaces for New Zealand. - Lincoln New Zeal.: 21.

Maina, J. N. 2017. Structure and Function of the Shell and the Chorioallantoic Membrane of the Avian Egg: Embryonic Respiration. The Biology of the Avian Respiratory System: Evolution, Development pp 219-244, Structure and Function. Springer, Berlin.

Maloney, S. K. 2008. Thermoregulation in ratites: A review. - Aust. J. Exp. Agric. 48: 1293-1301.

Mikhailov, K. E., Bray, E. S. and Hirsch, K. F. 1996. Parataxonomy of fossil egg remains (veterovata): Principles and applications. - J. Vertebr. Paleontol. 16: 763-769.

Moreno-Azanza, M. 2013. Unusual theropod eggshells from the Early Cretaceous Blesa Formation of the Iberian Range, Spain. - Acta Palaeontol. Pol. 59: 843-854.

Mueller, C. A., Burggren, W. W. and Tazawa, H. 2014. The Physiology of the Avian Embryo. - Elsevier. 
Norell, M. a, Clark, J. M., Demberelyin, D., Rhinchen, B., Chiappe, L. M., Davidson, a R., McKenna, M. C., Altangerel, P. and Novacek, M. J. 1994. A theropod dinosaur embryo and the affinities of the flaming cliffs dinosaur eggs. - Science 266: 779-782.

Paganelli, C. V 1980. the Physics of Gas-Exchange Across the Avian Eggshell. - Am. Zool. 20: 329-338.

Peebles, E. D. and Brake, J. 1986. The Role of The Cuticle in Water Vapor Conductance by the Eggshell of Broiler Breeders ,. - Poult. Sci. 65: 1034-1039.

Portugal, S. J., Maurer, G. and Cassey, P. 2010. Eggshell permeability: a standard technique for determining interspecific rates of water vapor conductance. - Physiol. Biochem. Zool. 83: 1023-1031.

Portugal, S. J., Maurer, G., Thomas, G. H., Hauber, M. E., Grim, T. and Cassey, P. 2014. Nesting behaviour influences species-specific gas exchange across avian eggshells. - J. Exp. Biol. 217: 3326-3332.

Prinzinger, R. and Dietz, V. 2002. Pre- and postnatal energetics of the North Island brown kiwi (Apteryx mantelli ). - Comp. Biochem. Physiol. A. Mol. Integr. Physiol. 131: 725-32.

Prinzinger, R., Schmidt, M. and Dietz, V. 1995. Embryogeny of oxygen consumption in 13 altricial and precocial birds. - Respir. Physiol. 100: 283-287.

Rahn, H. and Ar, A. 1980. Gas exchange of the avian egg time, structure, and function. - Integr. Comp. Biol. 20: 477-484.

Rahn, H. and Paganelli, C. V. 1990. Gas fluxes in avian eggs: Driving forces and the pathway for exchange. - Comp. Biochem. Physiol. - Part A Physiol. 95: 1-15.

Rahn, H., Paganelli, C. V. and Ar, A. 1974. The avian egg: air-cell gas tension, metabolism and incubation time. - Respir. Physiol. 22: 297-309.

Rahn, H., Carey, C., Balmas, K., Bhatia, B. and Paganelli, C. 1977. Reduction of pore area of the avian eggshell as an adaptation to altitude. - Proc. Natl. Acad. Sci. U. S. A. 74: 3095-3098.

Rahn, H., Ledoux, T., Paganelli, C. V and Smith, A. H. 1982. Changes in eggshell conductance after transfer of hens from an altitude of 3,800 to 1,200 m. - J. Appl. Physiol. 53: 1429-1431.

Ramstad, K. M. and Dunning, L. T. 2020. Population Genomics Advances and Opportunities in Conservation of Kiwi (Apteryx spp.). - In: Population Genomics. Springer, pp. 1-29.

Reid, B. 1971. The weight of the kiwi and its egg. - Notornis 18: 280-286.

Romanoff, A. L. and Romanoff, A. J. 1949. The avian egg. - avian egg.

Rowe, B. 1978. Incubation temperatures of the North Island brown kiwi (Apteryx australis mantelli ). Notornis 25: 213-217.

Rueden, C. T., Schindelin, J., Hiner, M. C., DeZonia, B. E., Walter, A. E., Arena, E. T. and Eliceiri, K. W. 2017. ImageJ2: ImageJ for the next generation of scientific image data. - BMC Bioinformatics 18: 1-26.

Silyn-Roberts, H. 1983. The pore geometry and structure of the eggshell of the North Island brown kiwi, Apteryx australis mantelli . - J. Microsc. 130: 23-36.

Sparks, N. H. C. and Board, R. G. 1984. Cuticle, Shell Porosity and Water Uptake Through Hens' Eggshells. - Br. Poult. Sci. 25: 267-276.

Taborsky, B. and Taborsky, M. 1999. The mating system and stability of pairs in kiwi Apteryx spp . - J. Avian Biol. 30: 143-151.

Tanaka, K., Zelenitsky, D. K. and Therrien, F. 2015. Eggshell Porosity Provides Insight on Evolution of Nesting in Dinosaurs. - PLoS One 10: 1-23. 
Thompson, M. B. and Goldie, K. N. 1990. Conductance and Structure of Eggs of Adelie Penguins, (Pygoscelis adeliae ), and Its Implications for Incubation. - Condor 92: 304.

Tullett, S. G. 1978. Pore Size Versus Pore Number in Avian Eggshells. - In: Respiratory function in Birs, Adult and Embryonic. pp. 219-226.

Tullett, S. G. 1984. The porosity of avian eggshells. - Comp. Biochem. Physiol. - Part A Physiol. 78: 5-13.

Tullett, S. G., Board, R. G., Love, G., Perrott, H. R. and Scott, V. D. 1976. Vaterite Deposition During Eggshell Formation in the Cormorant, Gannet and Shag, and in 'Shell-less' Eggs of the Domestic Fowl. Acta Zool. 57: 79-87.

Varricchio, D. J., Jackson, F. D., Jackson, R. A. and Zelenitsky, D. K. 2013. Porosity and water vapor conductance of two Troodon formosus eggs: an assessment of incubation strategy in a maniraptoran dinosaur. - Paleobiology 39: 278-296.

Vieco, D. 2019. The Egg and the Nest: Obtaining information about the reproductive biology of Apteryx spp. (Family: Apterygidae), a cryptic avian taxon, through eggshells. - [Doctoral dissertation] Massey University, Palmerston North, New Zealand.

Warning, N. and Benedict, L. 2015. Paving the way: Multifunctional nest architecture of the Rock Wren. Auk 132: 288-299.

Weir, J. T., Haddrath, O., Robertson, H. A., Colbourne, R. M. and Baker, A. J. 2016. Explosive ice age diversification of kiwi. - Proc. Natl. Acad. Sci.: 201603795.

Whittow, G. C., Pettit, T. N., Ackerman, R. A. and Paganelli, C. V 1987. Temperature regulation in a burrow-nesting tropical seabird, the Wedge-tailed Shearwater (Puffinus pacificus ). - J. Comp. Physiol. B Biochem. Syst. Environ. Physiol. 157: 607-614.

Wilkin, T. A., Gosler, A. G., Garant, D., Reynolds, S. J. and Sheldon, B. C. 2009. Calcium effects on life-history traits in a wild population of the great tit (Parus major): Analysis of long-term data at several spatial scales. - Oecologia 159: 463-472.

Ziesemann, B., Brunton, D. H. and Castro, I. C. 2011. Nesting success and breeding ecology in a high-density population of Brown Kiwi (Apteryx mantelli) . - Emu 111: 148-154.

Zimmermann, K., Hipfner, J. M. and Burger, A. E. 2007. Egg size, eggshell porosity, and incubation period in the marine bird family alcidae. - Auk 124: 307-315.

Table 1. Information regarding species and their weights, sites of origin of the eggshell samples, and conditions at the sample sites. DAI=Number of days in artificial incubation, EA=Estimated age at the start of incubation in captivity. *Average value for all Brown Kiwi samples. Data on weights from Castro and Morris (2011). Locations are $\mathrm{Co}=$ Coromandel, $\mathrm{To}=$ Tongariro, $\mathrm{Oh}=$ Ohope, $\mathrm{Ma}=$ Maungataniwha, $\mathrm{Pa}=\mathrm{Paparoa}$ National Park, Ok=Okarito Forest, $\mathrm{Ha}=$ Haast Sanctuary.

\begin{tabular}{lllllllll}
\hline Species & Location & $\begin{array}{l}\text { Max. } \\
\text { weight } \\
(\mathrm{Kg})\end{array}$ & $\begin{array}{l}\text { Max. } \\
\text { weight } \\
(\mathrm{Kg})\end{array}$ & $\begin{array}{l}\text { Co- } \\
\text { ordinates }\end{array}$ & $\begin{array}{l}\text { Co- } \\
\text { ordinates }\end{array}$ & $\begin{array}{l}\text { DAI } \\
(\text { Mean } \pm \text { SD) }\end{array}$ & $\begin{array}{l}\text { EA } \\
(\text { Mean } \pm \text { SD) }\end{array}$ & No. egg \\
\hline Brown & Oh Ma To & Males & Females & Lat & Long & & & \\
Kiwi & Co & & 2.8 & -37.980 & 177.028 & $26 \pm 12^{*}$ & $48 \pm 12^{*}$ & 3712 \\
& & & & -38.809 & 176.783 & & & \\
Roroa & $\mathrm{Pa}$ & 2.3 & 3.0 & -39.159 & 175.550 & & & \\
Rowi & $\mathrm{Ok}$ & 2.4 & 2.5 & -42.021 & 171.360 & unknown & unknown & 4 \\
Tokoeka & $\mathrm{Ha}$ & 2.3 & 3.0 & -43.273 & 170.176 & $39 \pm 12$ & $35 \pm 12$ & 25 \\
\hline
\end{tabular}


Table 2. Climatic data is an average of the monthly data from April 2015 to February 2016 obtained from World Weather Online (www.worldweatheronline.com/lang/en-nz). Locations are Co=Coromandel, $\mathrm{To}=$ Tongariro, $\mathrm{Oh}=$ Ohope, $\mathrm{Ma}=$ Maungataniwha, $\mathrm{Pa}=$ Paparoa, $\mathrm{Ok}=$ Okarito, $\mathrm{Ha}=$ Haast. Incubating strategy (IS) represents the involvement of parents in in the incubation process; $\mathrm{M}=$ male incubation only, $\mathrm{MF}=$ male and female, and $\mathrm{MF}-\mathrm{Co}=$ male, female and helpers.

\begin{tabular}{llllllll}
\hline Species & Location & IS & Pluviosity $(\mathrm{mm})$ & Pluviosity $(\mathrm{mm})$ & Temperature $\left({ }^{\circ} \mathrm{C}\right)$ & Temperature $\left({ }^{\circ} \mathrm{C}\right)$ & Pressure $(\mathrm{m}$ \\
\hline \multirow{3}{*}{ Kiwi } & & & Mean & SD & Mean & SD & Mean \\
& Co & M & 46.03 & 17.05 & 15.36 & 3.23 & 1017.35 \\
& To & & 39.92 & 21.13 & 9.18 & 4.26 & 1016.20 \\
& Oh & & 53.44 & 21.49 & 11.64 & 4.11 & 1016.73 \\
& Ma & & 27.80 & 18.43 & 13.27 & 3.64 & 1016.19 \\
Roroa & Pa & MF & 35.25 & 21.00 & 15.27 & 3.29 & 1017.68 \\
Rowi & Ok & MF & 104.35 & 35.34 & 4.00 & 4.75 & 1014.01 \\
Tokoeka & Ha & MF-Co. & 140.74 & 55.26 & 8.91 & 3.21 & 1014.09 \\
\hline
\end{tabular}

Table 3. Summary of the eggshell thickness and eggshell cuticle thickness obtained by scanning electron microscopy of the eggshell cross-section $(\mathrm{N}=64)$, superscripts next to the species name represent the Tukey post hoc test indicating which are the significantly different species. Roroa were not included in the analysis due to the very small sample size.

\begin{tabular}{llllll}
\hline & & $\begin{array}{l}\text { Total } \\
\text { Thickness } \\
(\mu \mathrm{m})\end{array}$ & MSE & $\begin{array}{l}\text { Cuticle } \\
\text { Thickness } \\
(\mu \mathrm{m})\end{array}$ & MSE \\
\hline Species & $\mathrm{N}$ & $304.77^{\mathrm{a}}$ & 9.93 & $4.07^{\mathrm{a}}$ & 0.23 \\
Brown Kiwi & 23 & $368.95^{\mathrm{b}}$ & 10.61 & $3.04^{\mathrm{b}}$ & 0.24 \\
Rowi & 21 & $383.96^{\mathrm{b}}$ & 12.56 & $3.03^{\mathrm{b}}$ & 0.29 \\
Tokoeka & 16 & F value 15.50 & p value $>0.0001$ & F value 6.16 & p value 0.004 \\
Roroa & 4 & 372.20 & 2.12 & 3.30 & 0.50 \\
\hline
\end{tabular}

Table 4. Summary of the pore density, and average pore radius. $P R=$ previously reported data (SylinRoberts, 1983).

\begin{tabular}{|c|c|c|c|c|c|c|c|c|c|}
\hline Species & $\mathrm{N}$ & $\begin{array}{l}\text { Pore } \\
\text { density } \\
\left(\text { pores } / \mathrm{cm}^{2}\right.\end{array}$ & $\begin{array}{l}\text { Pore } \\
\text { density } \\
2 \text { Xpores } / \mathrm{cm}^{2} \mathrm{PR}\end{array}$ & $\begin{array}{l}\text { Pore } \\
\text { radius* } \\
(\mu \mathrm{m})\end{array}$ & $\begin{array}{l}\text { Pore } \\
\text { radius* } \\
(\mu \mathrm{m})\end{array}$ & $\mathrm{N}$ & $\begin{array}{l}\text { Pore } \\
\text { radius[?] } \\
(\mu \mathrm{m})\end{array}$ & $\begin{array}{l}\text { Pore } \\
\text { radius[?] } \\
(\mu \mathrm{m})\end{array}$ & $\begin{array}{l}\text { Pore } \\
\text { radius[?] } \\
(\mu \mathrm{m})\end{array}$ \\
\hline & & Mean & MSE & Mean & MSE & & mean & $\mathrm{SE}$ & \\
\hline Kiwi & 13 & $51.3^{\mathrm{a}}$ & 3.12 & $22.90^{\mathrm{a}}$ & 2.81 & 3 & 18.43 & 0.40 & $11.23^{+}$ \\
\hline Rowi & 12 & $45.7^{\mathrm{ab}}$ & 3.25 & $33.04^{\mathrm{b}}$ & 2.69 & 2 & 32.79 & 0.43 & \\
\hline Tokoeka & 10 & $36.1^{\mathrm{b}}$ & 3.56 & $31.80^{\mathrm{ab}}$ & 3.81 & 2 & 18.27 & 1.75 & \\
\hline $\begin{array}{l}\mathrm{F} \\
\text { value }\end{array}$ & & 5.19 & 5.19 & 3.74 & 3.74 & & & & \\
\hline $\begin{array}{l}P \\
\text { value }\end{array}$ & & 0.012 & 0.012 & 0.04 & 0.04 & & & & \\
\hline Roroa & & & & & & 2 & 17.99 & 4.87 & \\
\hline
\end{tabular}

Superscripts indicate the statistical differences found using Tukey's test, values within columns with dif- 
ferent superscript are significantly different from each other (p[?]0.05). *Data obtained by measuring SEM images. ${ }^{* *}$ Data obtained by averaging three measurements along individual pores visualised using microCT. + Calculated from reported individual pore area.

Table 5. Spearman rank correlations between environmental variables and eggshell physical characteristics.

\begin{tabular}{lllllll}
\hline Eggshell character & $\mathrm{N}$ & Pluviosity & Pluviosity & Temperature & Temperature & Pressure \\
\hline & & Spearman coefficient & $p$-value & Spearman coefficient & $p$-value & Spearman coefficient \\
Eggshell thickness & 42 & $\mathbf{0 . 5 9}$ & $<\mathbf{0 . 0 0 1}$ & $\mathbf{- 0 . 5 1}$ & $<\mathbf{0 . 0 0 1}$ & $\mathbf{- 0 . 4 2}$ \\
Pore density & 37 & $\mathbf{- 0 . 5 1}$ & $\mathbf{0 . 0 0 1}$ & 0.11 & 0.51 & 0.10 \\
Pore radius & 29 & $\mathbf{- 0 . 3 6}$ & $\mathbf{0 . 0 5}$ & $\mathbf{- 0 . 4 3}$ & $\mathbf{0 . 0 2}$ & $\mathbf{- 0 . 4 0}$ \\
\hline
\end{tabular}

Statistically significant associations are in bold.

Table 6. Repeated measures analysis of the three different eggshell regions in the three species of Brown Apteryx

\begin{tabular}{llll}
\hline Species & Species & Species & Fragment \\
\hline & Least Square Mean & $\mathrm{SE}$ & \\
Kiwi $^{\mathrm{a}}$ & 0.24 & 0.013 & $\mathrm{~A}^{\mathrm{a}}$ \\
Rowi $^{\mathrm{b}}$ & 0.28 & 0.015 & $\mathrm{E}^{\mathrm{a}}$ \\
Tokoeka $^{\mathrm{a}}$ & 0.23 & 0.012 & $\mathrm{~B}^{\mathrm{b}}$ \\
$\mathrm{F}$-value & 3.15 & & $\mathrm{~F}$-value \\
$P$ value & 0.05 & & $P$ value \\
Interaction Species *Fragment & Interaction Species *Fragment & Interaction Species *Fragment & Interaction Species *Frag \\
F-value & 2.06 & & \\
$P$ value & 0.11 & & \\
\hline
\end{tabular}

The super script indicates significant differences

Table 7 Water vapour conductance values reported in the literature.

\begin{tabular}{lll}
\hline Water vapour conductance $(\mathrm{mg} /$ day.torr) & Source & $\mathrm{N}$ \\
\hline 26.00 & Calder (1978) & 5 \\
$23.71^{*}$ & Sylin-Roberts (1983) & 1 \\
40.84 & This study & 15 \\
\hline
\end{tabular}

*The value reported by Sylin-Roberts is based on a calculation of the pores on three eggshell fragments belonging to the same egg. 


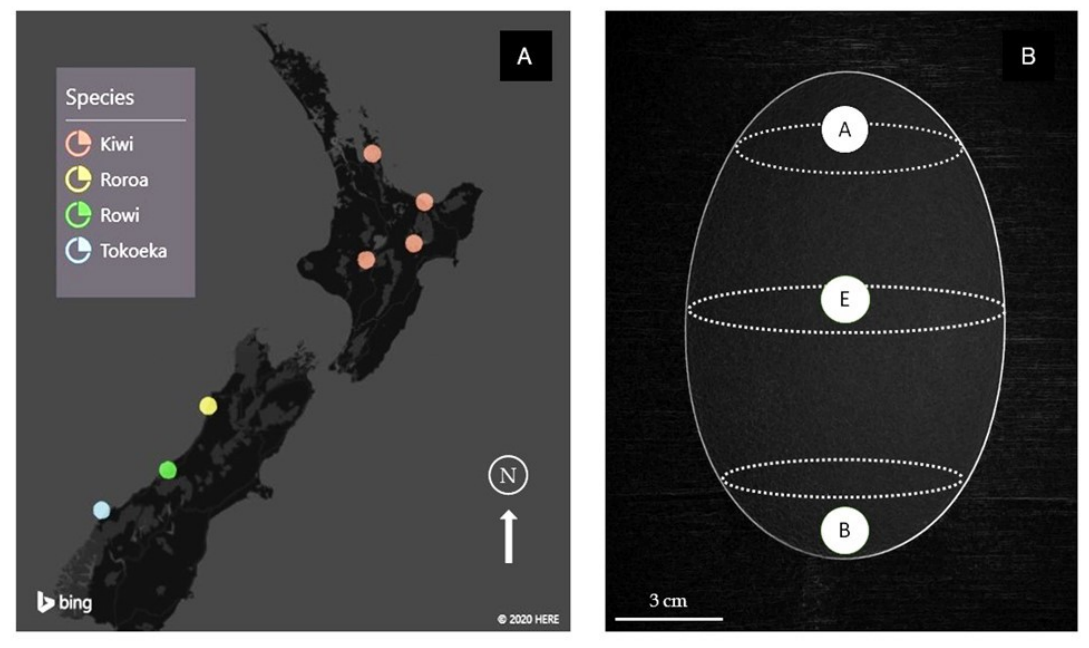



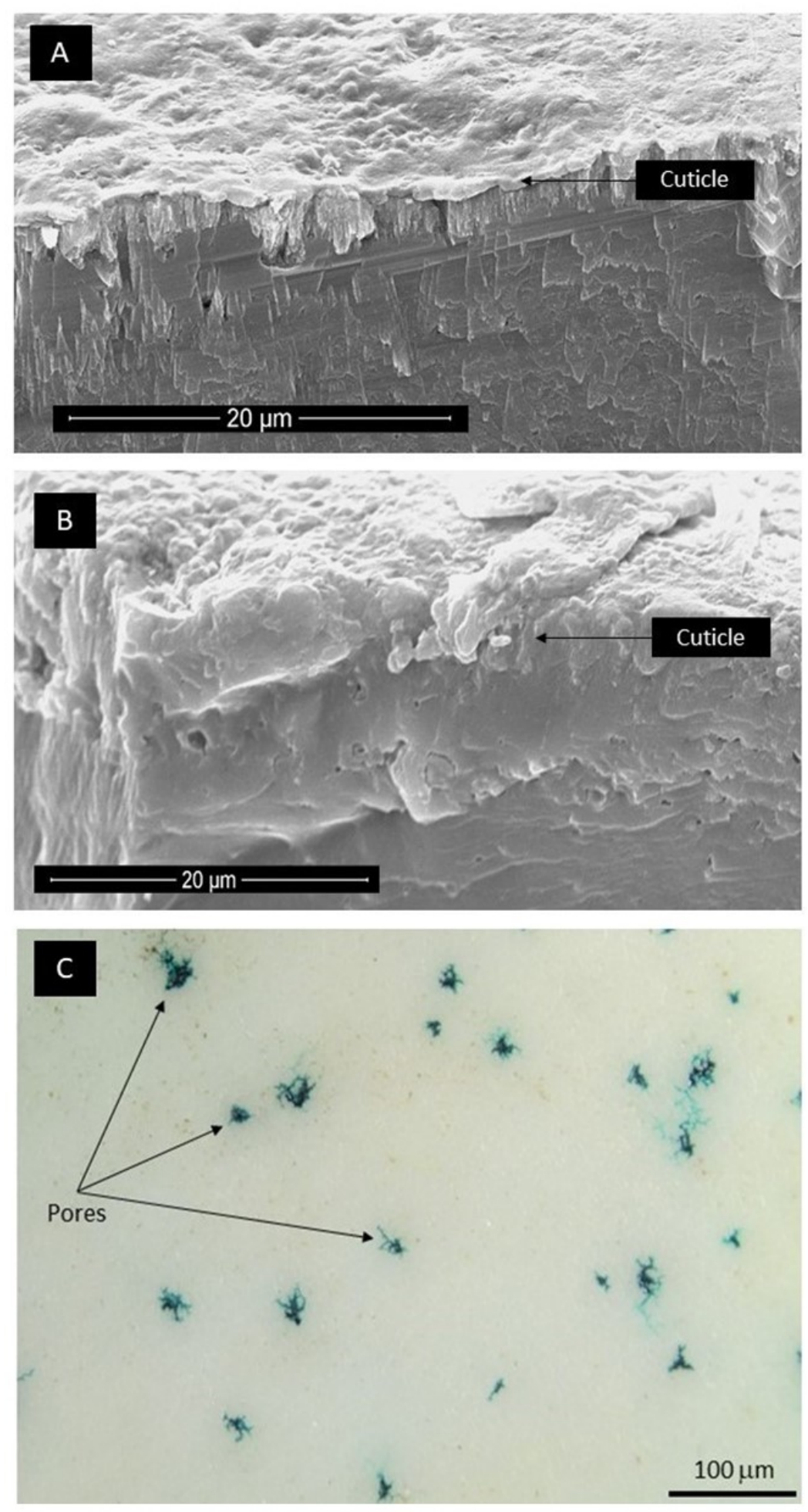

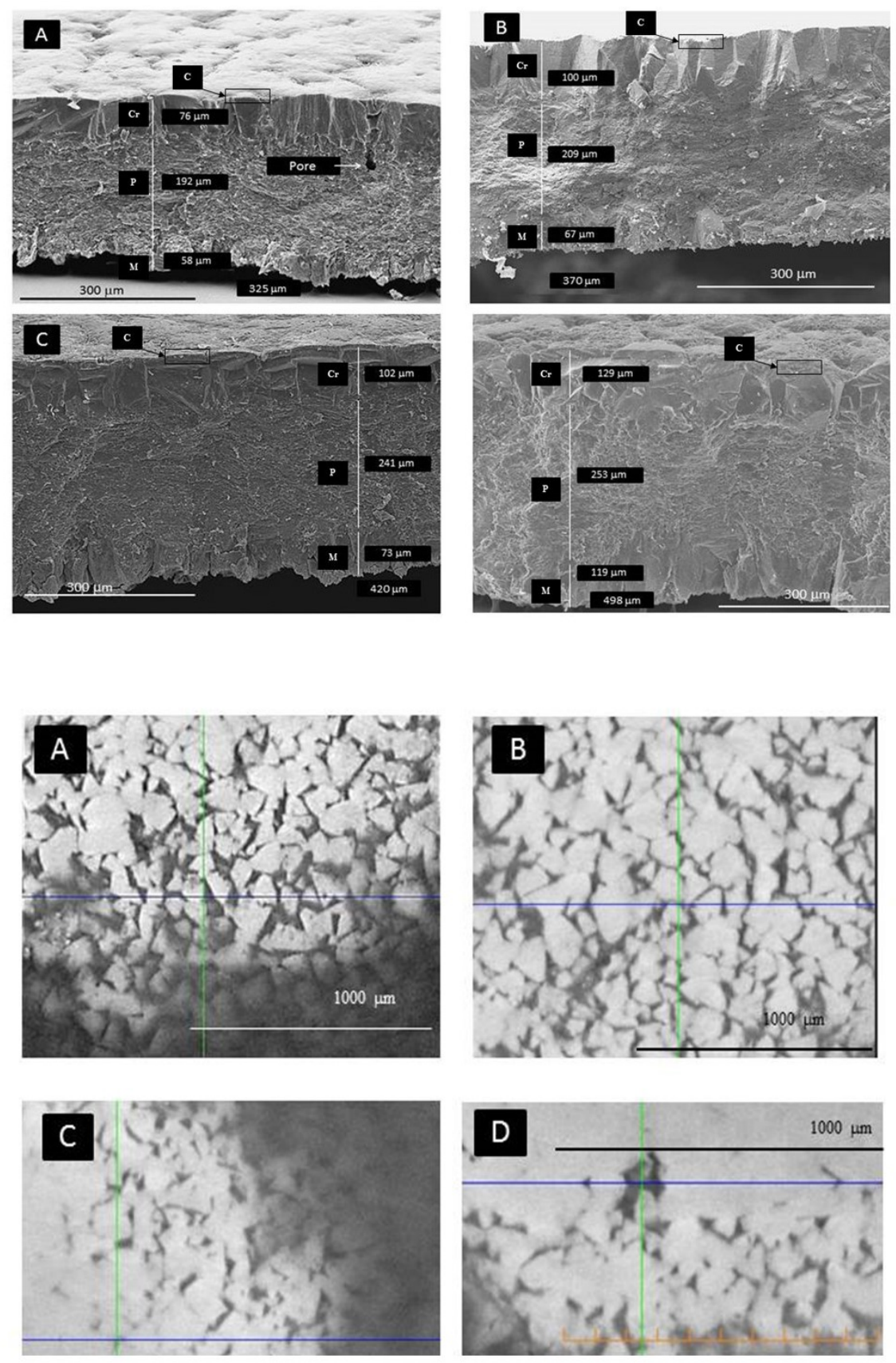

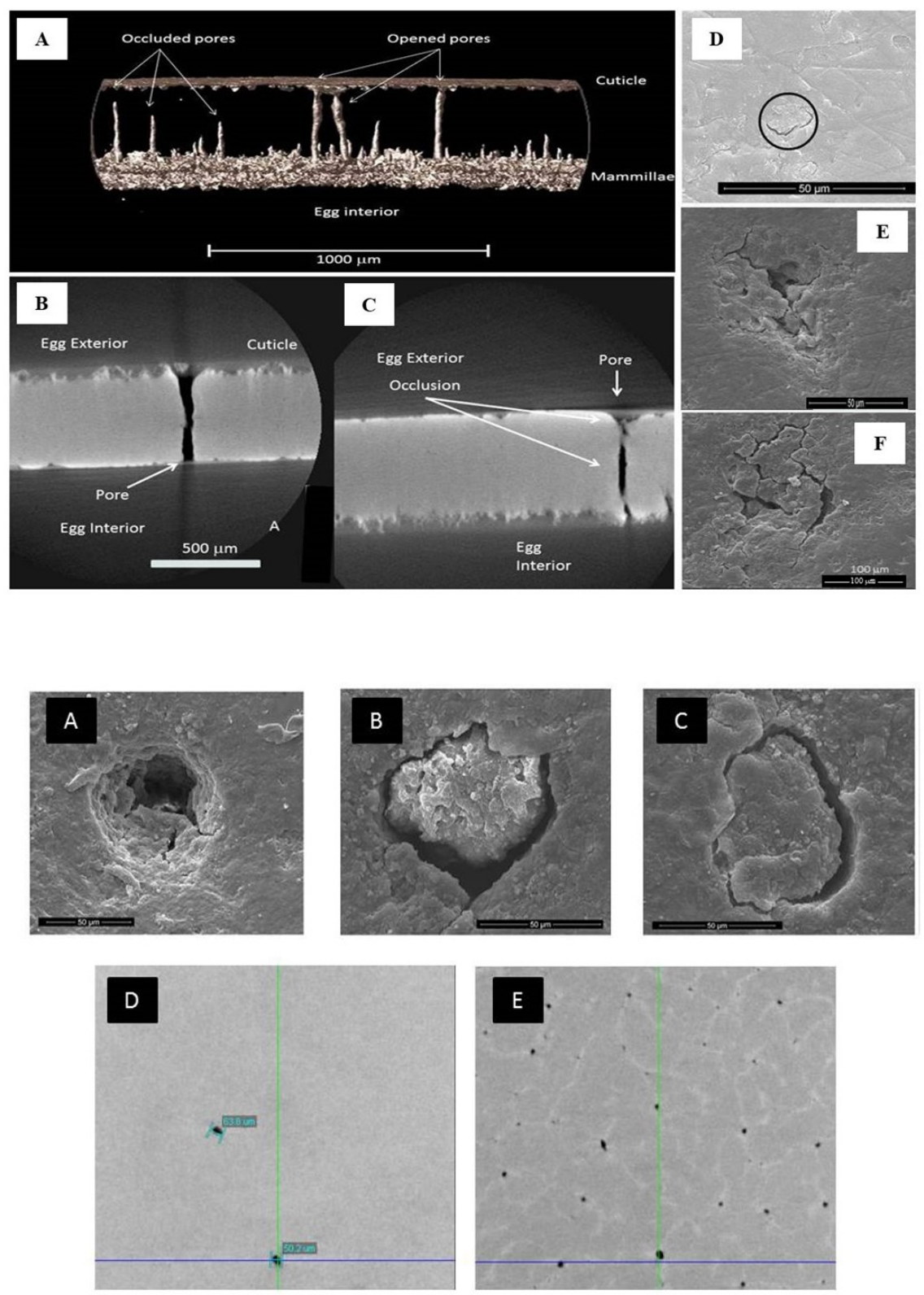
A

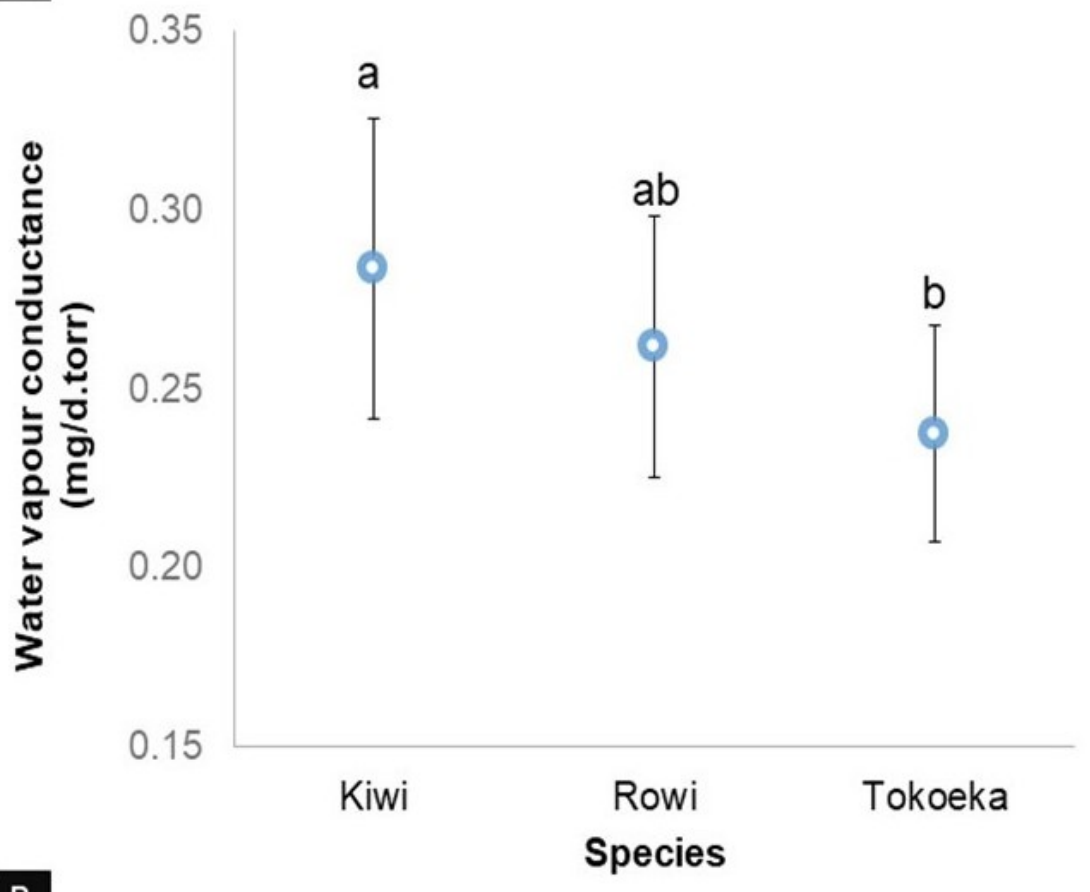

B

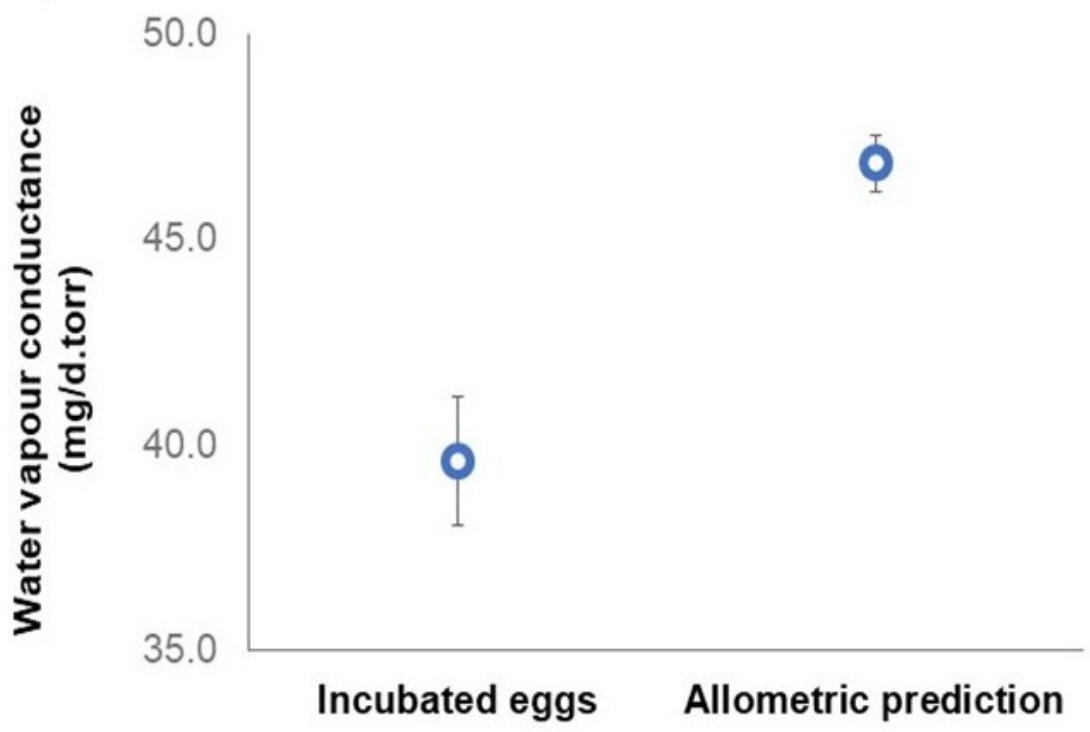




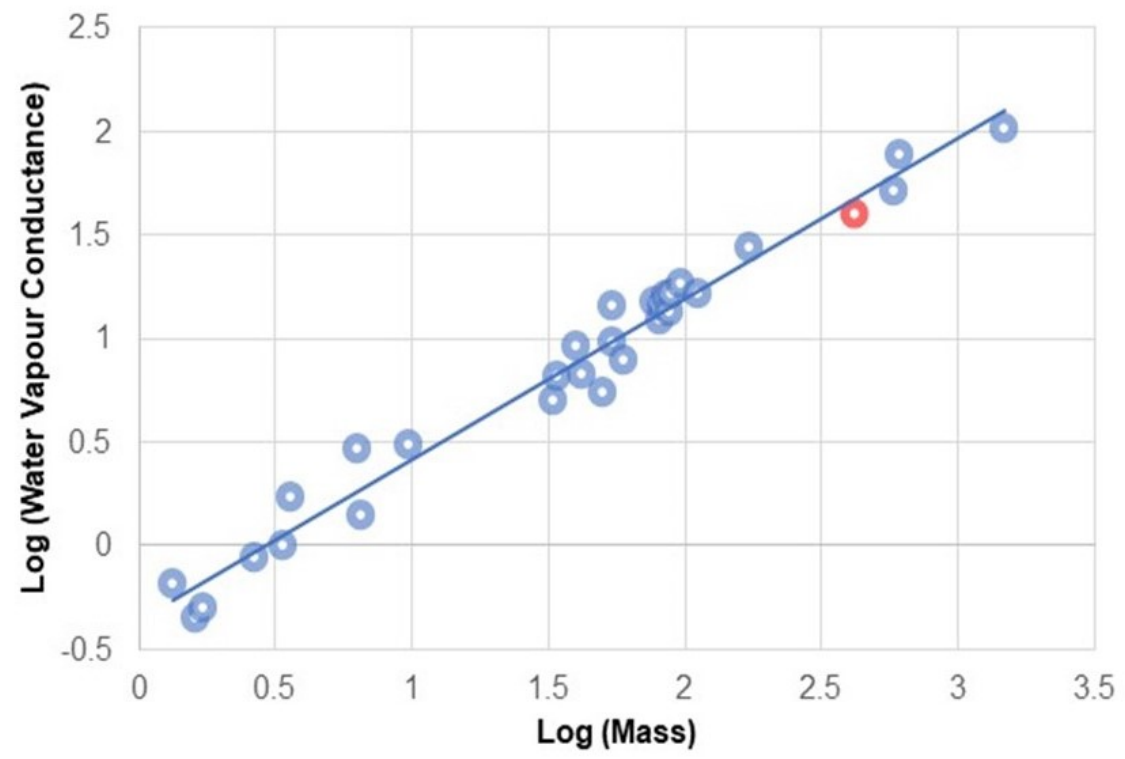

